\title{
A EDUCAÇÃO AMBIENTAL DO PONTO DE VISTA DAS CONCEPÇÕES DE DESENVOLVIMENTOO SUSTENTÁVEL NA ESCOLA DO CAMPO
}

\author{
Adaiana Mallmann ${ }^{1}$ \\ Irene Carniatto ${ }^{2}$ \\ Clério Plein ${ }^{3}$
}

Resumo: A Educação Ambiental no Brasil surge em resposta às constatações de que a degradação ambiental é capaz de esgotar os recursos naturais finitos do planeta. Dessa forma, passou a ser considerada responsável em sensibilizar as pessoas, guiando-as para o avanço da consciência ambiental. Ao ser trabalhada na educação formal essa temática objetiva formar cidadãos atuantes para o desenvolvimento sustentável. $\mathrm{O}$ presente estudo expõe o resultado de pesquisas bibliográficas e a análise de atividades que foram desenvolvidas em uma escola do campo no município de Marechal Cândido Rondon, buscando relacioná-las com as diferentes perspectivas de desenvolvimento sustentável.

Palavras-chave: Escola; Sustentabilidade; Educação Ambiental.

Abstract: Environmental Education in Brazil arises in response to the findings that environmental degradation can deplete the planet's finite natural resources. Thus, it was considered responsible for sensitizing people, guiding them towards the advancement of environmental awareness. When working on formal education this theme aims to train active citizens for sustainable development. The present study exposes the results of bibliographic research and the analysis of activities that were developed in a rural school in Marechal Cândido Rondon, aiming to relate them to the different perspectives of the sustainable development.

Keywords: School; Sustainability; Environmental Education.

\footnotetext{
1 Mestre em Desenvolvimento Rural Sustentável - PPGDRS. Universidade Estadual do Oeste do Paraná - UNIOESTE. Campus de Marechal Cândido Rondon. E-mail: adaiana2008@hotmail.com.

2 Pesquisadora e docente do Programa de Pós-Graduação em Desenvolvimento Rural Sustentável PPGDRS. Universidade Estadual do Oeste do Paraná - UNIOESTE. Campus de Marechal Cândido Rondon. E-mail: irenecarniatto@gmail.com.

${ }^{3}$ Bacharel em Economia Doméstica (UNIOESTE). Mestre e Doutor em Desenvolvimento Rural (UFRGS).

Professor Adjunto da UNIOESTE. E-mail: clerioplein@gmail.com.
} 


\section{Introdução}

O modo com que o ser humano se relaciona com a natureza ao longo da história foi sofrendo constantes adaptações. Aos poucos, a prática da exploração dos recursos naturais passou a ser alvo de análises e questionamentos por parte de pessoas que perceberam os prejuízos causados pela degradação dos ecossistemas. Frequentes alertas foram realizados, pois havia a possibilidade de acontecer o esgotamento de recursos naturais finitos, ou seja, de se instaurar uma crise ambiental.

Nesse contexto, a Educação Ambiental passou a ser considerada de suma importância para a sensibilização das pessoas a respeito da preocupação com a finitude dos recursos naturais. Desse modo, a educação formal no Brasil, numa ampliação de seus objetivos, incorporou essa temática nos currículos, por meio do desenvolvimento de diferentes atividades no âmbito das escolas com a finalidade de capacitar os cidadãos para que sejam atuantes no desenvolvimento sustentável ${ }^{45}$.

Assim como a Educação Ambiental, as perspectivas de desenvolvimento e de sustentabilidade refletem as diferentes concepções e bases epistemológicas inerentes ao momento histórico e contexto social vivido. Portanto, torna-se relevante descrevê-las ao longo desse estudo.

\section{Desenvolvimento}

A crise ambiental não representa uma novidade na história da humanidade. A sociedade já viu muitos de seus povos entrarem em colapso social e, até mesmo, desaparecerem. Para compreender a influência mútua que ocorre entre o ambiente e a sociedade, observa-se as contribuições de Diamond (2007), norte americano que seguiu carreira científica em Fisiologia, Biologia Evolutiva e Biogeografia. Os estudos revelam a problemática ambiental a partir da comparação entre as sociedades do presente e do passado e apontam fatores ambientais que explicam certos fatos sociais que determinaram o sucesso ou o fracasso de algumas civilizações.

Para o autor, o passado nos oferece um rico banco de dados com o qual podemos aprender e evitar futuros colapsos sociais, a exemplo das sociedades que outrora se mostraram bem-sucedidas, mas que, de alguma forma, falharam causando sua ruína. Com essas características observa-se,

\footnotetext{
${ }^{4}$ Esse artigo apresenta partes da dissertação de mestrado da autora intitulada

Desenvolvimento rural sustentável e Educação Ambiental: entre o discurso e a prática do Programa "Agrinho".

5 Considera-se que o Programa de Pós-graduação é em Desenvolvimento Rural Sustentável, assim sendo cabe uma discussão sobre Desenvolvimento Sustentável, ainda que o tema seja muito debatido no campo da Educação Ambiental. Busca-se em verdade uma comunidade Sustentável.
} 
entre outros exemplos, a Ilha de Páscoa, a Groelândia Nórdica, apontadas por Diamond (2007, p. 15) em seus estudos.

As recentes descobertas impulsionadas pelos avanços tecnológicos e científicos reforçam a suspeita do que o autor chamou de ecocídeo. De acordo com Diamond (2007, p.09), o ecocídio ocorreu quando os povos, inadvertidamente, esgotaram seus recursos naturais. Isso resultou na escassez de comida, fome e, consequentemente, guerras ocasionadas pela disputa dos poucos recursos disponíveis, dizimando sociedades completamente ou enfraquecendo-as drasticamente.

Mesmo com perspectivas tão radicais, Diamond (2007, p. 348) revela sua esperança ao afirmar que "temos a oportunidade de aprender com os erros de gente distante de nós no espaço e no tempo. Esta é uma oportunidade que nenhuma sociedade do passado desfrutou neste grau".

Apesar de ignorar outros fatores, como os genéticos e raciais, o autor apresenta relevantes contribuições para a discussão da problemática ambiental. Ao assumir as suas expectativas para o futuro das próximas gerações, Diamond (2007, p.346) revela-se um otimista cauteloso ao declarar: "Somos a causa de nossos problemas ambientais, temos controle sobre eles, e podemos escolher ou não parar de causá-los e começar a resolvê-los. O futuro está em nossas mãos".

De acordo com esse raciocínio, é possível afirmar que as ações das atuais gerações é que definirão as condições em que estará o mundo quando as crianças de hoje chegarem à velhice. No entanto, várias características atuais nos diferem das sociedades do passado, principalmente quando se considera a globalização, as ciências e tecnologias modernas, assim como a vantagem do poder potencializado pelo conhecimento sobre o passado.

Em tempos globalizados, é grande o potencial de interferência de ações isoladas locais nos demais contextos mundiais. As sociedades não estão sozinhas. Assim, é possível conhecer as dificuldades e as ações exitosas em todas as nações do planeta, a partir do uso das tecnologias, das relações mercadológicas e políticas típicas da globalização.

Ao referir-se aos efeitos nocivos da globalização, Dias (2004) aborda a preocupação dos cientistas na área ecológica ambiental, que expõem o alerta referente à "capacidade de suporte da terra e à viabilidade biológica da espécie humana” (DIAS, 2004. p.92). Ou seja, a globalização, de maneira geral, incentiva padrões de consumo que, em longo prazo, com o aumento considerável da população, tendem a exercer pressões sobre os recursos naturais finitos, sem levar em consideração sua capacidade de regeneração.

Nesse modelo, as formas de pensar e agir passam a ser orientadas por padrões que desconsideram todas as condições, atualmente, é possível considerar 8 valores (econômico, social, ambiental, cultural, estético, ético, político e metafísico/ espirituais) em conjunto, como defendem entre muitos autores, entre eles: Cantarelli (2012); Sachs (2008); Ribeiro Filho, Casaril, 
Carniatto, e Soares (2018). Essa reprodução, de acordo com Dias (2004) alimenta a formação de sentimentos de frustração e insatisfação, que desencadeiam efeitos prejudiciais à convivência social, como a violência e o estresse, por exemplo.

Da mesma forma, ao refletir sobre os impactos da globalização, Boff (2003) chama a atenção para a necessidade de reflexão sobre a ética, formação de valores e a responsabilidade social no contexto de uma crise estrutural que afeta as sociedades e passa a afetar todo o mundo.

Apesar de pontos de partida diferentes, é importante frisar as contribuições apontadas por Diamond (2007), ao reforçar a preocupação com a problemática ambiental, evidenciando o potencial das escolhas humanas nas relações com o ambiente natural e social, assim como a complementação das contribuições de Dias (2004) e Boff (2003), que delegam à reflexão e mudança de postura a missão de promover a sensibilização das pessoas a respeito das questões socioambientais.

De acordo com Leff (2010), a forte degradação ambiental gerada pelo crescimento econômico passou a ser discutida com mais ênfase nas últimas décadas do século XX e abriu campo para as diferentes estratégias que abordam a gestão ambiental. Assim, os inúmeros debates e pesquisas realizadas refletem a produção intelectual, de acordo com as especialidades e grupos econômicos ou ambientais que representam.

A crise ambiental passou a ser considerada pelos grupos econômicos a partir da manifestação de diversas problemáticas.

Até pouco tempo - o último terço do século $X X$ - estes problemas emergentes não se haviam manifestado nesta escala e com tal força, abrindo um campo até então não reconhecido pela economia - o equilíbrio ecológico, a preservação da biodiversidade e a qualidade de vida dos seres humanos -, não apenas como valores intrínsecos ou extraeconômicos, mas como condições fundamentais para a sustentabilidade da própria economia (LEFF, 2010, p. 20).

Para alguns grupos ambientais, o discurso propõe internalizar os custos ambientais e os princípios da sustentabilidade à economia, resultando num equilíbrio com condições sustentáveis do planeta. Dessa forma, as diferentes posições apresentadas debatem suas perspectivas. Sachs (2009, p.60) aponta a necessidade de uma combinação que seja possível entre ecologia e economia, "pois as ciências naturais podem descrever o que é preciso para um mundo sustentável, mas compete às ciências sociais a articulação das estratégias de transição rumo a este caminho".

Nesse contexto, ainda é necessário para Sachs (2009, p.60) "reconceitualizar o desenvolvimento como apropriação efetiva de todos os direitos humanos, políticos, sociais, econômicos e culturais, incluindo-se aí o 
direito coletivo ao meio ambiente". De acordo com Leff (2010) são necessários novos processos de significação da natureza e de sentidos existenciais que sejam capazes de resultar em um novo modo de produção e de racionalidade ambiental.

Assim, a percepção dos riscos ao modelo econômico vigente e suas consequências para o bem-estar social e qualidade de vida da população desencadearam movimentos que mostraram para o mundo as agressões ao ambiente, num importante alerta sobre como o mesmo é usado tanto para a exploração econômica quanto como para o depósito de seus resíduos, sem a devida preocupação com as gerações que ainda estão por vir.

A opinião pública mundial sobre a vida no planeta, conforme Sachs (2008) foi sofrendo alterações após a constatação das possibilidades do avanço tecnológico e do poder técnico dos seres humanos sobre a natureza, com potencial tanto para amenizar as dificuldades quanto para agravar a crise ambiental.

A percepção de que a humanidade deve ser analisada a partir da integração entre desenvolvimento e meio ambiente é resultante da crença nas virtudes do progresso técnico e a atenção às diferentes escalas de tempo, uma vez que, para a natureza a recuperação pode levar décadas, séculos ou até mesmo milênios e, também, devido à preocupação com as consequências das ações locais que podem interferir em todo o planeta ou mesmo em regiões distantes dali.

Com a contribuição da ciência é possível estabelecer relações com a natureza de forma sustentável, de maneira a satisfazer as necessidades humanas, limitando os princípios da ganância e compreendendo os recursos naturais como finitos. "O conceito de recurso é cultural e histórico. É o conhecimento pela sociedade, do potencial do seu meio ambiente" (SACHS, 2009 p.70).

Para Sachs (2002) é necessário que se mude os padrões de oferta e consumo no mundo, para que a biosfera recupere sua capacidade de reposição natural. Essa mudança acarretará alterações no estilo de vida, na forma de educação e conscientização da autorregulação humana.

Da mesma forma, a necessidade de mudanças é declarada por Boff (2003), que chama a atenção para a importância da mobilização política com instituição do princípio da responsabilidade pela humanidade e pelo planeta, com discussão ética, com mudança de comportamento e pela adoção de novos valores que reflitam no cuidado e preocupação com o futuro do planeta.

O princípio ético a que Boff (2003) se refere é o da solidariedade com as futuras gerações, sem ignorar a grande parcela de excluídos do presente. Suas análises levam em consideração os imediatismos impostos pela globalização e a centralidade no individualismo, uma vez que desconstroem a visão do todo e dificultam as reivindicações em prol da sobrevivência do planeta. Essa abordagem demonstra a necessidade de planejamento em longo 
prazo, de forma a estabelecer vínculos coletivos e éticos com o ambiente natural e social que primem pela qualidade de vida compartilhada por todos.

A preocupação em estabelecer os vínculos é tratada por Boff (2016), como a inteligência emocional, "pois ela nos faz sentir parte de um todo maior, que nos dá a conexão com os demais seres". Cuidar do planeta significa cuidar da casa comum, a Terra. Assim, uma sociedade sustentável incentiva a participação de seus cidadãos para que estejam conscientes da biocapacidade e das condições essenciais para a qualidade de vida.

Como afirma Freire (1996), os seres humanos, históricos, sociais e culturais precisam da liberdade de aprender, de comparar, de escolher, de decidir, de aceitar ou de recusar. Munidos de conhecimento é possível questionar e analisar o modelo de desenvolvimento imposto ou proposto pelos setores econômicos e ambientais.

A educação é essencial para o desenvolvimento, pelo seu valor intrínseco, na medida em que contribui para o despertar cultural, a conscientização, a compreensão dos direitos humanos, aumentando a adaptabilidade e o sentido de autonomia, bem como a autoconfiança e a autoestima (SACHS, 2008, p. 40).

A alternativa proposta para mudar essa situação é o desenvolvimento sustentável que refletirá em um novo estilo de vida e tem como estratégia a promoção da Educação Ambiental.

O termo "desenvolvimento sustentável" está explícito nos trabalhos do economista Ignacy Sachs, que estudou as relações entre desenvolvimento e o meio ambiente, por meio das propostas da Comissão Brundtland, organizada pela ONU em 1983, cujo resultado foi exposto no relatório "Nosso Futuro Comum" em 1987, que manteve as propostas de articular o crescimento econômico, preservação ambiental e equidade social.

De acordo com Dias (2004, p. 120), a partir desse relatório, as perspectivas de desenvolvimento sustentável compreendem: "atender as necessidades do presente, sem comprometer a possibilidade de as gerações futuras atenderem às suas próprias necessidades". O debate das questões ambientais e de desenvolvimento sustentável tem influenciado diferentes campos do saber, principalmente a educação. Observam-se, nas últimas décadas, amplas discussões entre organismos nacionais e internacionais, governamentais ou não, que direcionam a proposta de educação para a sustentabilidade.

Ao considerar a evolução dos conceitos de Educação Ambiental, Dias (2004, p.101) destaca que este é "um processo por meio do qual as pessoas aprendam como funciona o ambiente, como dependemos dele, como afetamos e como promovemos a sustentabilidade". 
Ao analisar a Educação Ambiental como proposta para a sustentabilidade, Lima (2002) afirma que esta não atingiu os resultados esperados devido à complexidade da crise contemporânea que é, segundo o autor, resultado de práticas que reduzem a crise ambiental a uma proporção exclusivamente ecológica, que apresentam confusão na compreensão fragmentada de meio ambiente como natureza e ignoram suas dimensões políticas, éticas e culturais, desprezando a crítica à questão socioambiental por meio de uma abordagem interdisciplinar, além de "propor respostas comportamentais e tecnológicas para problemas de maior complexidade".

No Brasil, principalmente a partir da década de 90, a Educação Ambiental vem sendo campo de estudos e debates de inúmeros pesquisadores e educadores. Em 1997, a I Conferência Nacional de Educação Ambiental debateu as dificuldades, desafios e propôs recomendações para que 0 conteúdo de Educação Ambiental tivesse seus objetivos atingidos.

Entre os desafios destacam-se àqueles em relação à fragmentação do conhecimento em áreas. Nas escolas isso se consolida nas variadas disciplinas, com lacunas nos diferentes níveis e modalidades de ensino. A elaboração dos materiais didáticos, de caráter informativo, que ignoram questões sociais, econômicas e culturais reforçam visões reducionistas em Educação Ambiental. Além disso, na formação docente percebe-se a ausência de uma visão integrada em questões éticas e epistemológicas na construção do conhecimento em Educação Ambiental. Desse modo, a compreensão do meio ambiente apenas como representação da natureza reflete a dificuldade das disciplinas em interagir de forma integrada com todas as outras áreas do conhecimento, restando ao professor mediar essa importante discussão.

De acordo com Lima (2002), diante da "polissemia que caracteriza o discurso da sustentabilidade", a preocupação está em discutir criticamente as concepções que envolvem as ações educativas, quais conteúdos estão implícitos em suas práticas, seus objetivos e valores de forma que não se efetivem numa "expressão vazia e duvidosa".

Realizar atividades de Educação Ambiental descontextualizadas ou mesmo sem oportunizar a análise e a reflexão teórica, evidencia-se a efetivação de uma ação obsoleta e desnecessária, conforme postulado por Lima (2002). Ao se esvaziar o significado e a importância da Educação Ambiental, cria-se a oportunidade para as meras reproduções, tão combatidas pela concepção histórico-crítica da educação.

A prática de uma educação que se contrapõe à uma educação para a liberdade, conforme postulado por Freire (1967) expressa sua preocupação, contextualizada num momento da história brasileira em que o exercício da democracia estava limitado por questões de ordem social, econômica e política, e, assim, expôs sua concepção educacional diante das possibilidades de mobilização e manipulação das classes: 
Uma educação que possibilitasse ao homem a discussão corajosa de sua problemática. De sua inserção nesta problemática. Que o advertisse dos perigos de seu tempo, para que, consciente deles, ganhasse a força e a coragem de lutar, ao invés de ser levado e arrastado à perdição de seu próprio "eu", submetido às prescrições alheias. Educação que o colocasse em diálogo constante com o outro. Que o predispusesse a constantes revisões (FREIRE, 1967, p. 90).

Vistas dessa forma, as concepções de Freire (1967) têm validade em outros espaços e tempos, sendo que a busca de respostas para os desafios está permeada pela prática educativa, em que o ser humano é sujeito de sua história.

De uma educação que levasse o homem a uma nova postura diante dos problemas de seu tempo e de seu espaço. A da intimidade com eles. A da pesquisa ao invés da mera, perigosa e enfadonha repetição de trechos e de afirmações desconectadas das suas condições mesmas de vida (FREIRE, 1967 p. 93).

Assim, supõe-se que a educação deva ser a ferramenta para a compreensão necessária do contexto e assim permitir os avanços do desenvolvimento sustentável? A resposta está condicionada aos princípios éticos e bases epistemológicas a que o desenvolvimento desejado representa.

Compreender a educação como um instrumento para um fim determinado está implícito em grande parte dos documentos e estudos norteadores da Educação Ambiental, como afirma Lima (2002), com sugestões para mudanças adaptativas de posturas e valores sustentáveis "sem ultrapassar os limites da conformidade".

Esse "conservadorismo dinâmico", que realiza mudanças superficiais para garantir que o essencial seja conservado, representa talvez o maior obstáculo à concepção e implementação de uma proposta complexa e transformadora de sustentabilidade. Esse é um obstáculo que uma educação crítica e integradora pode ajudar a superar (LIMA, 2002, p. 12).

Compreender a crise socioambiental de forma crítica exige do educador a problematização e o conhecimento que considere a diversidade de concepções de sustentabilidade, seus valores, posições éticas, políticas e as implicações sociais. E assim como afirma Freire (1983), o conhecimento oportuniza participar da realidade e dialogar com outras verdades e assim poder melhor transformá-la. 
De acordo com Lima (2002), a abordagem do tema sustentabilidade deve considerar o contexto em que está sendo inserida, problematizando a diversidade de argumentos favoráveis e contrários ao discurso. De modo que a ação educativa capacite para a comparação, debate e o julgamento individual. Considera-se pertinente a ação educativa que estimula a problematização, a pesquisa, a seleção e a comparação de dados e que leve em consideração diferentes expectativas.

No Brasil, a Educação Ambiental passou a ser responsável em formar cidadãos conscientes capazes de contribuir para uma sociedade sustentável, como está disposto na lei ํo 9795/99 que institui a Política Nacional de Educação Ambiental:

Art. 1ํㅡㄹ Entendem-se por Educação Ambiental os processos por meio dos quais o indivíduo e a coletividade constroem valores sociais, conhecimentos, habilidades, atitudes e competências voltadas para a conservação do meio ambiente, bem de uso comum do povo, essencial à sadia qualidade de vida e sua sustentabilidade.

Art. 2 A Educação Ambiental é um componente essencial e permanente da educação nacional, devendo estar presente, de forma articulada, em todos os níveis e modalidades do processo educativo, em caráter formal e não-formal.

São objetivos fundamentais da Educação Ambiental:

Art. 5:: O desenvolvimento de uma compreensão integrada do meio ambiente em suas múltiplas e complexas relações, envolvendo aspectos ecológicos, psicológicos, legais, sociais, econômicos, científicos, culturais e éticos (BRASIL, 1999).

Com a aprovação da Lei no 9.795, de 27 de abril de 1999 e do seu regulamento, o Decreto no 4.281, de 25 de junho de 2002, que instituiu a Política Nacional de Educação Ambiental (PNEA), houve o amparo legal para as ações em prol do meio ambiente.

Desse modo, a Educação Ambiental realizada em ambiente formal ou informal assume a função de sensibilizar e capacitar os indivíduos para a tomada de decisão, objetivando que sejam conscientes das consequências das relações entre os homens, a sociedade e a natureza.

A implementação da Educação Ambiental por meio das políticas educacionais brasileiras, valida e estimula as práticas educativas interdisciplinares, de tal forma que cada vez mais instituições privadas, associações, cooperativas e órgãos governamentais incentivam essas ações nas escolas, propondo a participação dos alunos e professores em programas específicos ou no envolvimento em concursos e no desenvolvimento de 
projetos, de forma que, potencialmente, promovem-se diante da opinião pública ao proclamar suas ações vinculando-as aos discursos de sustentabilidade.

Num mundo globalizado, de acordo com Bonfim e Filho (2013), a opinião pública tem o poder de interferir nas exigências dos mercados, uma vez que questões sociais, ambientais, tecnológicas e étnicas resultam nas escolhas dos processos produtivos e de comercialização. Dessa forma, pode-se compreender como o sucesso da comercialização, no modo de produção capitalista vigente é dependente da opinião pública e, por consequência, a qualidade de vida das populações.

Nessa conjuntura, também se observa a realização de abordagens no contexto da Educação Ambiental que priorizam de forma fragmentada os impactos ambientais em detrimento de suas causas geradoras. Como exemplo pode-se citar situações em que são analisados problemas da esfera de consumo (destino do lixo, economia de energia...) desconsiderando os processos da produção, até sua destinação.

Os impactos ambientais causados pelos resíduos sólidos costumam ser abordados em ações educativas que acontecem nas escolas. Muitas vezes sua abordagem resume-se à coleta seletiva ou reutilização. Ignora-se os conteúdos implícitos que podem ser abordados, entre outros, cita-se por exemplo: ao reutilizar uma garrafa pet como vaso para flores ou chás é possível estudar também as relações entre insetos e as plantas, a importância da planta para a conservação da água e do solo e valorizar a adubação orgânica. No entanto, o fator que poucas vezes é alvo de análises e pesquisas é conhecer o processo de produção da garrafa pet, seu impacto no ambiente na extração da matéria prima e no seu descarte incorreto, assim como também questões culturais, sociais e mercadológicas de seu uso.

Para realizar a análise de atividades de Educação Ambiental que foram desenvolvidas na modalidade de ensino formal, destaca-se, para esse estudo, as ações do Grêmio Estudantil de uma escola do campo no município de Marechal Cândido Rondon. As ações envolveram todos os alunos da escola e aconteceram desde o início do ano letivo. Ao indagar aos alunos sobre as ações do grêmio Estudantil estes relataram que o objetivo era o de desenvolver a consciência da sustentabilidade em toda a comunidade escolar.

Os alunos desenvolveram ao longo do ano o projeto: Nossa Escola: Um Ambiente de Sustentabilidade, com a realização de diferentes atividades, entre as quais se destacam: $1,2,3)$

- Confecção de artesanato utilizando materiais recicláveis (Figuras 



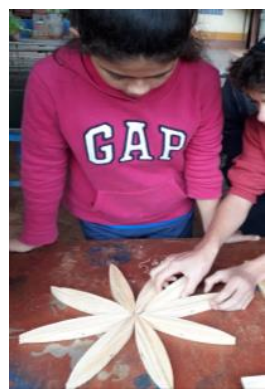

Figura 1: Oficina de artesanato com madeira. Fonte: Da autora, 2019.

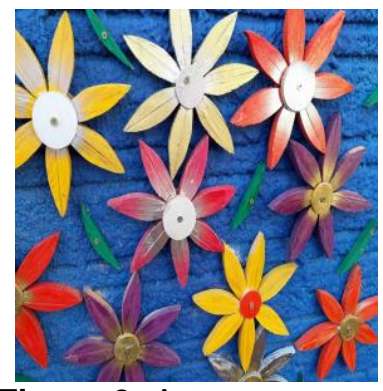

Figura 2: Artesanato com madeira.

Fonte: Da autora, 2019.

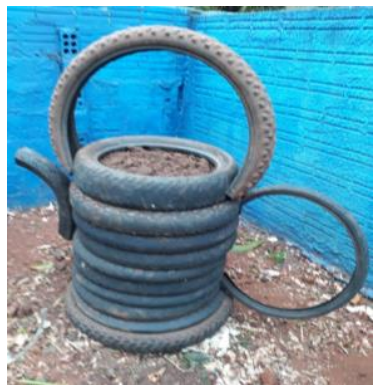

Figura 3: Reutilização de pneus.

Fonte: Da autora, 2019

Para as oficinas de artesanato foram utilizados pedaços de madeira que costumam ser descartados de uma marcenaria e os pneus que se transformaram em objetos de decoração no pátio da escola. Para a realização destas atividades os alunos contaram com ajuda do zelador e da secretária do colégio, que se responsabilizaram em ministrar a oficina educativa.

- Recolha de lacres de latas de alumínio, pilhas e baterias usadas, óleo de cozinha usado (Figura 4);

- $\quad$ Arrecadação de roupas e calçados usados, para a feira de poucos reais (Figura 5).

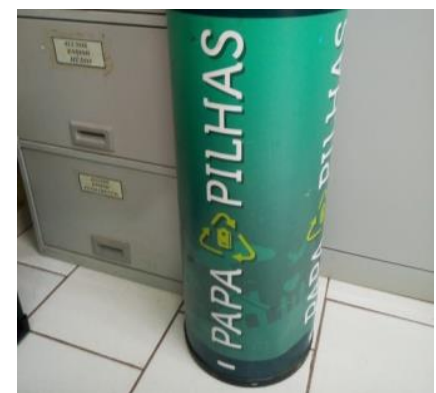

Figura 4: Caixa receptora de pilhas e baterias. Fonte: Da autora, 2019.

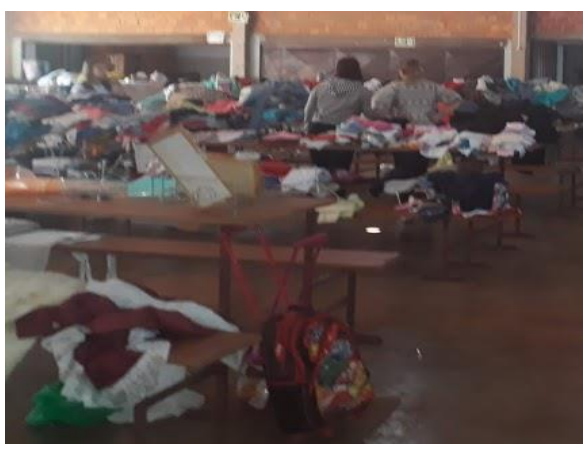

Figura 5: Feira de poucos reais. Fonte: Da autora, 2019.

A caixa receptora de pilhas e baterias usadas faz parte da parceria entre a escola e uma cooperativa da cidade.

O óleo de cozinha usado foi revendido para uma empresa que produz biocombustível. Neste caso, além da campanha pelo descarte correto dos produtos que a escola realiza, esta se transformou num ponto de coleta para a comunidade.

A feira de roupas e calçados usados aconteceu depois de intensa campanha de incentivo pela doação. Os materiais foram expostos durante a feira de poucos reais, toda a comunidade foi convidada a participar. Os recursos financeiros provenientes da venda do óleo de cozinha usado e da feira de poucos reais foram revertidos aos alunos em materiais escolares. 
- Produção e cultivo de horta com hortaliças e ervas medicinais (Figuras 6, 8);

- Ajardinamento (Figura 7);

- Plantio de mudas de árvores silvestres (Figura 9);

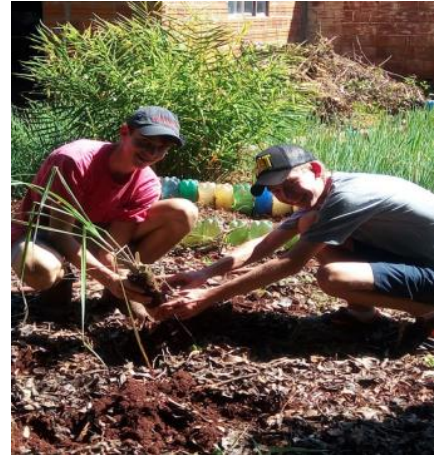

Figura 6: Plantio de ervas medicinais. Fonte: Da autora, 2019.

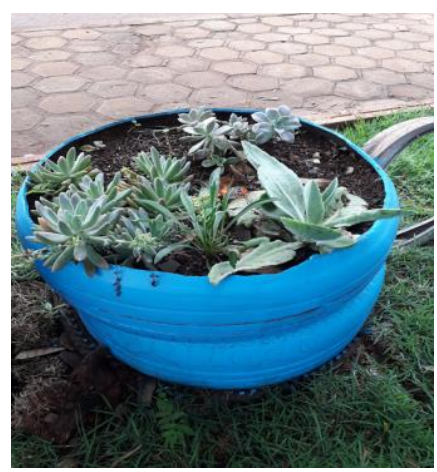

Figura 7: Ajardinamento. Fonte: Da autora, 2019.

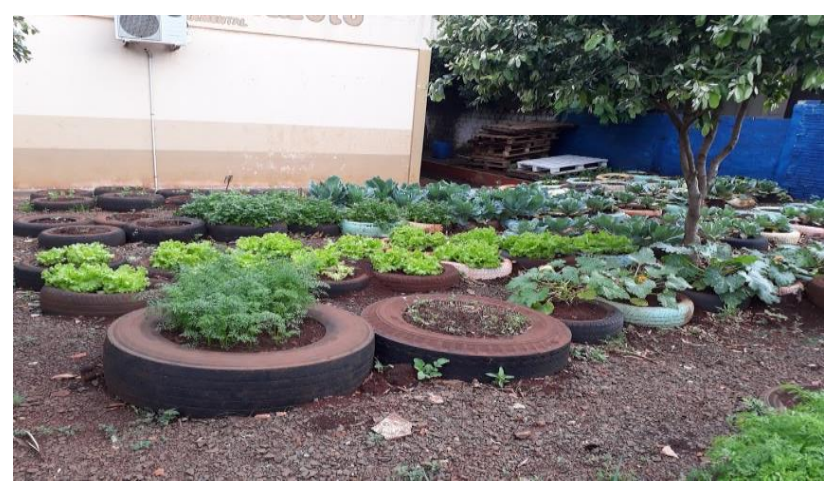

Figura 8: Cultivo da horta. Fonte: Da autora, 2019.

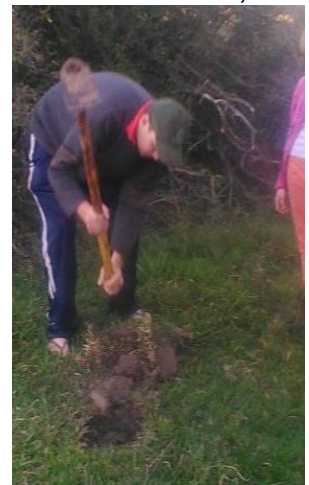

Figura 9: Plantio de árvores silvestres.

Fonte: Da autora, 2019.

O cultivo da horta e das plantas medicinais foi realizado com a parceria das famílias dos alunos que doaram mudas e adubos. Para o plantio e preparo do solo, os alunos contaram com a ajuda do zelador da escola e seus familiares. Assim, aplicaram os conhecimentos adquiridos em sala de aula sobre as plantas e o solo, além de serem incentivados a adquirir hábitos de alimentação saudável. A campanha de incentivo para o plantio de árvores nativas foi realizada após a sensibilização sobre a importância delas para toda a biodiversidade local e quem teve interesse, pôde levar mudas para serem cultivadas em áreas adequadas. As mudas foram doadas pela Itaipu Binacional.

- Realização de desfile cívico com cartazes de alerta e sensibilização (Figura 10); 


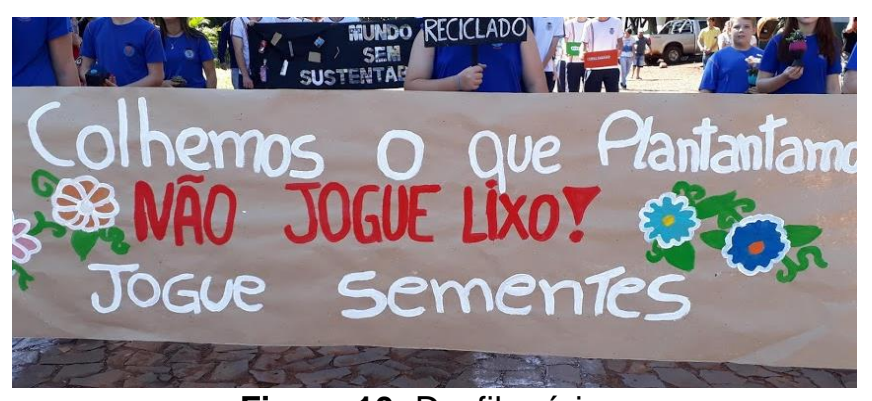

Figura 10: Desfile cívico.

Fonte: Da autora, 2019.

Por ocasião do desfile cívico, que aconteceu no dia 07 de setembro de 2018, os alunos carregaram faixas e cartazes com frases que chamavam a atenção para questões relacionadas ao cuidado com o meio ambiente, como resultado dos conteúdos estudados em sala de aula e as atividades do projeto “Nossa Escola: Um Ambiente de Sustentabilidade" realizado ao longo do ano.

Atendeu-se à recomendação dos documentos oficiais com a observância da prática da Educação Ambiental de forma transdisciplinar e interdisciplinar, uma vez que os alunos que fazem parte do Grêmio Estudantil executaram as atividades ao se reunirem para discutir e problematizar o contexto em que a escola está inserida, envolvendo os conteúdos estudados nas diferentes disciplinas da grade curricular. Após a análise de possíveis soluções para as problemáticas abordadas, envolveu-se os demais integrantes da comunidade escolar na reflexão e na execução das atividades propostas.

Durante o desenvolvimento do projeto quantificou-se alguns de seus resultados (Tabela 1).

Tabela 1: Quantidade de itens arrecadados durante a Corrida do Ouro.

\begin{tabular}{|c|c|}
\hline Roupas e pares de calçados usados & 4946 unidades \\
\hline Óleo de cozinha usado & 206 Litros \\
\hline Pilhas e baterias usadas & 2332 unidades \\
\hline Lacres de latinhas & 303670 unidades \\
\hline
\end{tabular}

Fonte: Da autora, 2019.

Estima-se o envolvimento direto de 200 pessoas entre alunos, professores e, indiretamente, suas famílias e comunidade em geral.

Destaca-se que a comunidade está localizada na zona rural do município e a destinação dos resíduos sólidos constitui-se em um grave problema, que suscita a atuação da Educação Ambiental. Um exemplo disso são as atividades realizadas com 0 projeto. Estas comprovaram essa dificuldade, uma vez que os alunos problematizaram seu entorno após as devidas reflexões. No entanto, estas ações do projeto não demonstraram a análise e a necessidade de reflexão entre a produção e consumo.

De acordo com Lima (2004) a produção e o consumo não podem ser analisados separadamente. Nesse processo estão envolvidas as escolhas de 
como? com o quê? Quanto? e por que produzir? Além de abordar questões individuais e de comportamento como a sua solução. Ignora-se valores culturais implícitos nos padrões de consumo (LAYRARGUES, 2011). Dessa forma, o tema gerador deve analisar, questionar as causas e consequências. Nessa perspectiva, os resíduos sólidos podem, por exemplo, abordar cinco categorias: saúde pública, estética, custos de recolhimento e processamento, depósitos e o esgotamento dos recursos naturais.

Ações educativas desenvolvidas nas escolas através de projetos ambientais contam, em boa parte, com parcerias de empresas privadas. Um exemplo são as ações de estímulo de reciclagem que, muitas vezes, omitem a redução e o reaproveitamento, ou ignoram a reflexão sobre o consumismo desmedido. Um exemplo é a reciclagem de latinhas de alumínio, que desconsidera o estímulo ao consumo de refrigerante e o uso de embalagens retornáveis. Verifica-se assim a fragmentação da realidade e a exposição unilateral de sua totalidade.

A participação de entidades privadas como parceiras de projetos escolares é facilmente detectada na atividade de recolha de pilhas e baterias usadas como no Projeto "Nossa Escola: Um Ambiente de Sustentabilidade". No município uma Cooperativa realiza ao longo de todo o ano a campanha de recolha de pilhas e baterias com o projeto Papa Pilhas, deixando nas escolas uma caixa receptora. A Cooperativa responsabiliza-se em destinar corretamente esses resíduos, enfatizando sua campanha pela sustentabilidade e enaltecendo diante da opinião pública seu comprometimento com o meio ambiente e com a cidadania.

O verdadeiro cidadão consciente e responsável, não é aquele que escolhe consumir preferencialmente produtos recicláveis, mas aquele que cobra do Poder Público, por meio de processos coletivos de pressão, que o mercado ponha um fim na obsolescência planejada e na descartabilidade, e, sobretudo que exige do Estado a implementação de políticas públicas que destruam os mecanismos perversos de concentração de renda (LAYRARGUES, 2011, p.221).

Algumas ações educativas refletem a preocupação com o consumismo desmedido e a concentração de renda. Ações como a coleta de roupas e calçados usados, artigos domésticos que permitem seu reuso e a posterior doação aos menos favorecidos socialmente, são estratégias que atingem seus objetivos quando realizados em conjunto com a análise do contexto histórico, social e econômico das populações, caso contrário, remete-se à ideia do conformismo e acomodação da condição vigente.

As atividades de produção e cultivo de horta com hortaliças e ervas medicinais, o ajardinamento e a realização de desfile cívico com cartazes de alerta e sensibilização constituem-se em ações que pretendem desenvolver a 
consciência ambiental para a sustentabilidade e buscam, na sua maioria, promover a reflexão e a mudança de postura, vindo ao encontro das afirmações de Dias (2004) e Boff (2003).

Nos discursos de Educação Ambiental reforça-se o debate da participação social e do exercício da cidadania. No entanto, é preciso diferenciar o modelo de participação tutelada e conservadora do modelo ativo e autônomo, ações capazes de legitimar a manutenção das desigualdades sociais e camuflar a igualdade jurídica.

A Educação Ambiental promovida por entidades não governamentais também tende a propagar discursos heterogêneos entre si, de certa forma disputando posições e interesses na esfera social (LIMA, 2002).

A ação educativa também é prática política, pois para sua execução são necessários subsídios e escolha de ações pedagógicas que orientam para alguma direção. Então como atuar na Educação Ambiental?

Não há receitas prontas e acabadas, o caminho possível é a percepção da responsabilidade humana pela degradação ambiental. Também deve ser considerada a possibilidade de diálogo e negociações na busca de soluções para a crise socioambiental, com perspectivas de mudanças de ordem cultural, social, espacial, econômica e ambiental.

\section{Conclusões}

Para que ocorra efetivamente a participação das populações na tomada de decisão é necessário a capacitação e a troca de experiências que envolvam êxitos e fracassos, a fim de estimular a criatividade na busca de soluções, assim como assumir a responsabilidade por seus efeitos.

O exercício da cidadania também tem seus reflexos nas ações de participação e fiscalização das políticas que são aplicadas. A disponibilização de capacitações constitui-se na oferta de subsídios para o exercício da autonomia, oportunizando a eliminação de desperdícios, a poupança de recursos e o planejamento. A Educação Ambiental vista, dessa forma, tem como ponto de partida as necessidades individuais e coletivas na Casa Comum de todos seres vivos (BOFF, 2016).

Dessa forma, ao se instigar a curiosidade pelo mundo e realidade alheia é possível elaborar diferentes estratégias, que passam a ser adaptadas para sua realidade de forma que aconteça a "reinvenção" do conhecimento trazido pelo educador. Resulta dessa ação o sujeito que se compreende inserido num contexto e capaz de agir conscientemente na transformação do mundo.

Diferentes iniciativas realizadas pela educação formal têm como objetivo o diálogo, a solidariedade e a participação social. Ações que podem fortalecer a construção de uma nova ética, que valorize não apenas a vida humana, mas todo o complexo ecossistema. 
Ao estabelecer semelhanças e diferenças entre fatos na intenção de compreender as contradições presentes nas relações sociais e sensibilizar o educando aproximando-o da realidade, fortalece-se no aluno a capacidade de pensar por si próprio, de compreender seu lugar no mundo e de seu potencial de transformação.

Ações de Educação Ambiental nas escolas devem apresentar temas de acordo com a faixa etária dos alunos, a partir de uma perspectiva individual, do entorno imediato do estudante. Para as crianças é fundamental recorrer aos cinco sentidos, participar de visitas, atividades de reflexão, jogos coletivos ou individuais. Para alunos maiores é possível a intervenção direta em exercícios de simulação, após o estudo da problemática e intenso debate.

A experiência educacional que envolve ações práticas e diretas é muito mais eficaz, conforme postulado por Piletti, (2004), quando se envolve os sentidos: o ato de ler, pesquisar, ouvir e executar ou ensinar consiste na aprendizagem mais efetiva.

A Educação Ambiental não formal deve contribuir para a participação em ações coletivas que estimulem os cidadãos a refletir e cobrar do poder público ações que melhorem a qualidade dos produtos que são oferecidos, que questionem sua obsolescência e descartabilidade, que cobrem a qualidade dos serviços prestados e estimulem a participação dos cidadãos nos recursos educacionais que thes são oferecidos, como museus, parques, trilhas, ações turísticas, culturais e esportivas, entre outros.

De acordo com Dias (2004), a qualidade de vida e a sobrevivência da humanidade dependem do valor que as pessoas atribuem ao cuidado e proteção dos recursos ambientais e a consideração e solidariedade com as futuras gerações.

\section{Agradecimentos}

Ao apoio da Coordenação de Aperfeiçoamento de Pessoal de Nível Superior - Brasil (CAPES); à Universidade Estadual do Oeste do Paraná pela oferta do Programa de Pós-Graduação em Desenvolvimento Rural Sustentável, por tornar possível o grau de mestre da autora.

\section{Referências}

BOFF, L. A ética e a formação de valores na sociedade. Rev. Reflexão. Instituto Ethos. Ano 4, no 11, outubro de 2003.

BOFF, L. Sustentabilidade: o que é - o que não é. $5^{\text {a }}$ Ed. revista e ampliada. Petrópolis - RJ: Vozes, 2016. 
BONFIM, R.M.F.; HILDO, M.S. Oportunidades e desafios para a inserção de pequenos produtores em mercados modernos. In: CAMPOS, S.K.; NAVARRO, Z. (Org.) A pequena produção rural e as tendências do desenvolvimento agrário brasileiro: ganhar tempo é possível? Brasília: CGEE, p. 71 a 100, 2013.

BRASIL. LEI № 9.795, de 27 de abril de 1999. Dispõe sobre a Educação Ambiental, institui a Política Nacional de Educação Ambiental e dá outras providências. Disponível em <http://www.planalto.gov.br/ccivil 03/leis/L9795. htm>. Acesso em 25 jun. 2018.

BRASIL. Decreto Federal no 4.281, de 25 de junho de 2002. Regulamenta a Lei no 9.795, de 27 de abril de 1999, que institui a Política Nacional de Educação Ambiental, e dá outras providências. Disponível em $<$ http://www.planalto.gov.br/ccivil 03/decreto/2002/d4281.htm>. Acesso em 25 jun. 2018.

DIAMOND, J. Colapso - Como as sociedades escolhem o fracasso ou o sucesso. RAPOSO, Alexandre (trad.). 5a ed. Rio de Janeiro/ São Paulo: Ed. Record, 2007.

DIAS, G.F., Educação Ambiental: princípios e práticas. 9ª Ed. São Paulo. Gaia. 2004.

FREIRE, P. Educação Como Prática da Liberdade. Rio de Janeiro: Paz e Terra. 1967.

FREIRE, P. Extensão ou comunicação. $7^{\text {a }}$ ed. Rio de Janeiro: Paz e Terra, 1983.

FREIRE, P. Pedagogia da autonomia: saberes necessários à prática educativa. São Paulo: Paz e Terra, 1996.

LAYRARGUES, P.P. O cinismo da reciclagem: o significado ideológico da reciclagem da lata de alumínio e suas implicações para a Educação Ambiental. In: LOUREIRO, C.F.B. LAYRARGUES, P.P.; CASTRO, R.S. (Org.) Educação Ambiental: repensando o espaço da cidadania. $5^{\underline{a}}$ Ed. São Paulo: Cortez, p. 185-225, 2011.

LEFF, E. Discursos sustentáveis. Trad. Silvana Cobucci Leite. São Paulo: Cortez, 2010.

LIMA, G.F.C. Educação, emancipação e sustentabilidade: em defesa de uma pedagogia libertadora para a Educação Ambiental. In: LAYRARGUES, P.P. (coord) Identidades da Educação Ambiental brasileira. Ministério do Meio Ambiente. Dir. Educação Ambiental. Brasília. Ministério do Meio Ambiente, p.85 $-111,2004$. 
LIMA, G.F.C. Educação e sustentabilidade: possibilidade e falácias de um discurso. Encontro Associação Nacional de Pós Graduação e Pesquisa em Ambiente e Sociedade, 1, 2002, Indaiatuba. [Anais...] Indaiatuba, 2002 Disponível em: <http://anppas.org.br/encontro anual/encontro1/gt/sociedade do conhecimento/Gustavo\%20F.\%20Costa\%20Lima.pdf>. Acesso em 23 jul. 2018.

MALLMANN, A. Desenvolvimento rural sustentável e Educação Ambiental: entre o discurso e a prática do Programa "Agrinho". 2019. 145 f. Dissertação (mestrado), Centro de Ciências Agrárias, Programa de Pós-Graduação em Desenvolvimento Rural Sustentável, Universidade Estadual do Oeste do Paraná, Marechal Cândido Rondon, 2019.

PILETTI, C. Didática geral. 23a ed. São Paulo: Ática, 2004. Disponível em: $<$ https://praxistecnologica.files.wordpress.com/2014/08/piletti didaticageral.pdf> Acesso em 01 nov. 2018.

SACHS, I. A Terceira Margem: em busca do ecodesenvolvimento. São Paulo: Companhia das Letras, 2009.

SACHS, I. Caminhos para o desenvolvimento sustentável. $2^{\circ} \mathrm{Ed}$. Rio de Janeiro: Garamond, 2002.

SACHS, I. Desenvolvimento: includente, sustentável, sustentado. Rio de Janeiro: Garamond, 2008. 